This is a preprint of a paper published as:

Van Steen, C., Verstrynge, E., Wevers, M., Vandewalle, L. (2019). Assessing the bond behaviour of corroded smooth and ribbed rebars with acoustic emission monitoring. Cement and Concrete Research. (Paper accepted for publication)

\title{
Assessing the bond behaviour of corroded smooth and ribbed rebars with acoustic emission monitoring
}

\author{
Charlotte Van Steen ${ }^{\mathrm{a}, *}$, Els Verstrynge ${ }^{\mathrm{a}}$, Martine Wevers ${ }^{\mathrm{b}}$, Lucie Vandewalle ${ }^{\mathrm{a}}$ \\ ${ }^{a}$ Department of Civil Engineering, KU Leuven, Leuven, Belgium \\ ${ }^{b}$ Department of Materials Engineering, KU Leuven, Leuven, Belgium
}

\begin{abstract}
Corrosion of the reinforcement is one of the major deterioration problems in existing reinforced concrete (RC) structures. One of the important damage modes is the deterioration of the bond between steel and concrete. In this paper, the acoustic emission (AE) technique is evaluated for damage detection, characterisation and localisation during the corrosion process and during pull-out tests. AE monitoring is applied during accelerated corrosion as well as during pull-out tests, in combination with standard inspection techniques such as crack width measurements. RC prisms with smooth or ribbed reinforcement were corroded up to different corrosion levels: $0 \%$, $1.5 \%, 5 \%$ and $10 \%$ mass loss. The corrosion process was accelerated in the laboratory. One of the specimens of each rebar type at every corrosion level was monitored continuously with the AE technique. At the target corrosion levels, pull-out tests were carried out to study the bond capacity. During these tests, AE monitoring was performed on every specimen. Results show that $\mathrm{AE}$ is able to detect damage during the corrosion progress and that the moment of crack initiation can be determined from the cumulative AE event curves. During the pull-out tests, debonding damage was successfully detected, characterised and located based on AE data.
\end{abstract}

Keywords: reinforcement corrosion, acoustic emission, bond strength, pull-out

\section{Introduction}

Corrosion of the reinforcement is regarded to be the most common and most expensive deterioration mechanism in existing reinforced concrete (RC) structures. Dedicated research to quantify the effects of the degradation processes on the structural capacity and durability of RC mem5 bers is challenging, timely and necessary in order to develop assessment schemes for existing RC structures. Reinforcement corrosion causes a number of interacting damage modes: overall/local

\footnotetext{
${ }^{*}$ Corresponding author. Tel.: +32 16374521

Email address: charlotte.vansteen@kuleuven. be (Charlotte Van Steen)
} 


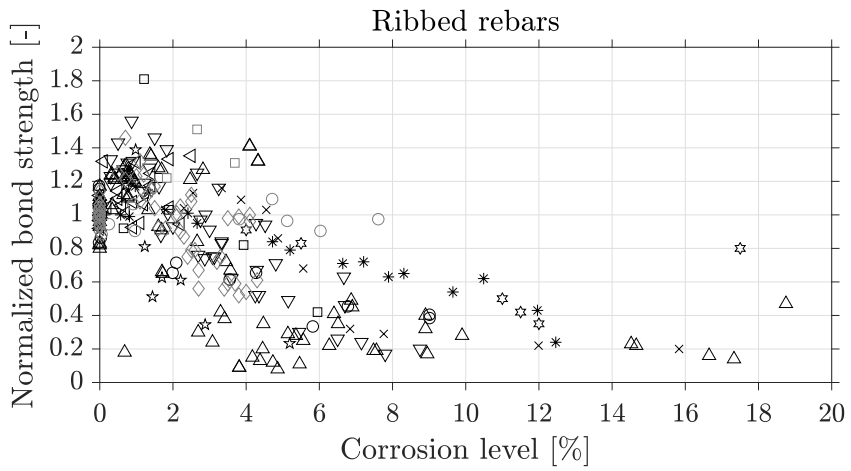

$\triangle$ Yalciner et al. (2012), unconfined

Almusallam et al. (1996), unconfined

Zhao et al. (2013), unconfined

* Cabrera (1996), unconfined

$\triangleleft$ Chung et al. (2008), unconfined

- Fang et al. (2004), unconfined

$\nabla$ Al-Sulaimani et al. (1990), unconfined

t Auyeung et al. (2000), unconfined

\& Amleh and Mirza (1999), unconfined

Fang et al. (2004), confined

Zhao et al. (2013), confined

Wu et al. (2016), confined

Figure 1: Normalised bond strength versus corrosion level for samples with ribbed rebars.

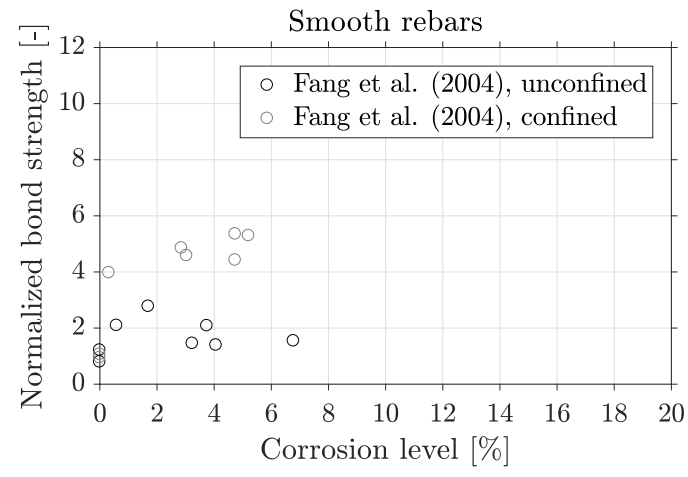

Figure 2: Normalised bond strength versus corrosion level for samples with smooth rebars.

section reduction of the rebar, tensile stresses in the concrete due to the expansive nature of corrosion products causing concrete cracking and spalling, a reduction in ductility of the rebar and degradation of the bond within the reinforcement-concrete interface. Bond deterioration is hereby one of the important damage modes. Studies have shown that for certain structural elements the loss of bond strength for unconfined reinforcement is more critical than the loss of cross section [1. The loss of bond can go up to $80 \%$ while the reduction of the cross section is rather low [2].

Extensive research has been performed by several authors on the bond behaviour of concrete elements with corroded reinforcement, including samples with smooth or ribbed rebars and with or without lateral confinement (stirrups). Although studies of corrosion effects on smooth rebars are scarce, the presence of such rebar types in many mid 20th century RC structures clearly justifies the need for their inclusion in current investigations. A brief literature study on the effect of corrosion on the bond strength is presented below. For an extensive review, the reader is referred to Lundgren [3]. The bond strength depends on several parameters such as rebar type (smooth or ribbed) 2 [4, diameter of the rebar [5] 6] 7, the water-cement ratio [8 9], the presence of lateral confinement [2] 10, and the thickness of the concrete cover [6] 8] 9]. Some authors adapted the wellknown centric pull-out test to a cantilever bond test [11, used cylindrical samples [12] or corroded the rebars before casting them [13]. The different experimental results reported in literature for smooth and ribbed rebars were compared in relation to the obtained corrosion level and are shown 


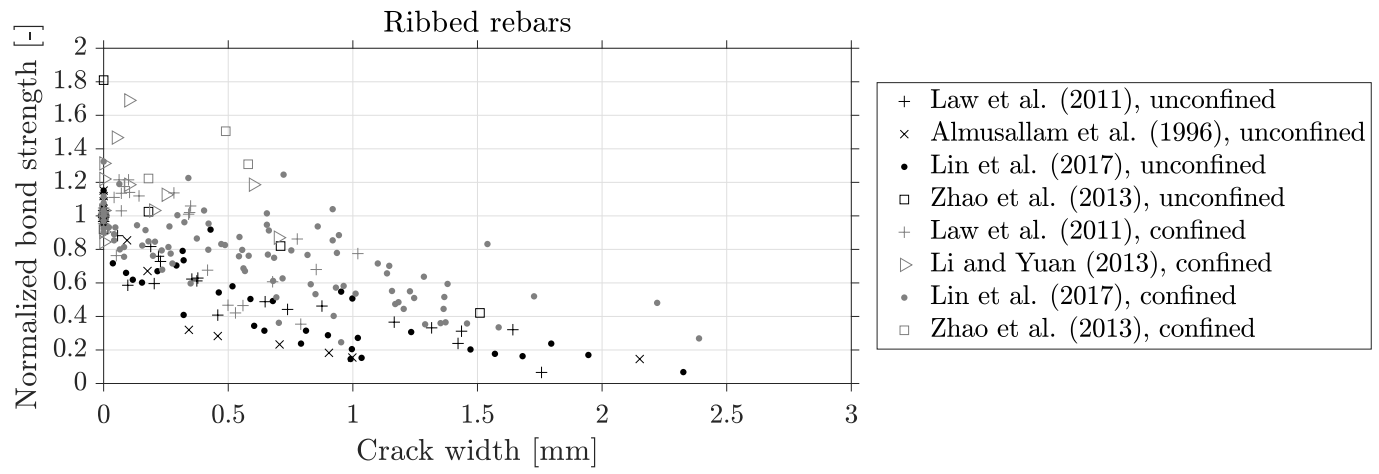

Figure 3: Normalised bond strength versus crack width induced by corrosion for samples with ribbed rebars.

in figure 1 and figure 2. A limited number of results of samples with smooth reinforcement can be seen. Recently, interest in the relation between the bond strength and the crack width is growing as the latter can easily be measured on-site. An overview is shown in figure 3 [14 15 [16]. As different concrete mixtures and sample sizes were used for each experimental campaign, the normalised bond strength was calculated in order to compare the results. The normalised bond strength is defined as the bond strength of each sample divided by the average bond strength of the non-corroded samples. A small amount of corrosion (0-4\% mass loss) has a positive effect on the bond strength. For higher corrosion levels, the bond strength decreases. Typically, the bond strength decreases when cracks reach the surface. When a sample is cracked, a positive effect can only be noticed for confined samples.

35 On-site quantification of structural damage requires advanced non-destructive techniques (NDT) for material and damage characterisation. Electrochemical techniques are widely used to monitor corrosion on-site. Unfortunately, they are dependent on climate conditions and they might lack to provide precise information. This increases the demand for calibration with other techniques. A very promising technique to capture not only the corrosion process itself, but also the progress of concrete cracking is the acoustic emission (AE) technique. Local stress redistributions in the material, such as cracking, emit high frequency elastic waves that can be recorded by AE sensors on the concrete surface [17]. The technique has proven its efficiency for localising corrosion damage in metal structures, such as pressure vessels and pipelines, where direct contact with the metal is possible [18] 19]. AE monitoring has been succesfully applied during rebar corrosion in concrete and destructive testing of corroded RC samples and components [20] 21] 22]. The technique has high potential for corrosion monitoring on full-scale RC structures but still poses some challenges such as filtering in noisy environments and path-dependent distortion of signals by cracking. To account for this, dedicated experimental work is necessary to upscale this technique.

The aim of this paper is to evaluate the effect of different corrosion levels on the bond strength of reinforced concrete samples with ribbed and smooth rebars, and to evaluate the applicability of the AE technique for damage monitoring during the corrosion process, and during pull-out testing. The former is an initial investigation to assess the applicability of the AE technique for on-site corrosion monitoring in RC structures. In the latter case, AE sensing is applied to obtain a better understanding of the pull-out process on smooth and ribbed rebars. 


\section{Experimental Approach}

\subsection{Materials and specimen preparation}

Two types of specimens were compared during the experimental program: specimens reinforced with a smooth rebar and specimens reinforced with a ribbed rebar. Four different corrosion levels were targeted for each rebar type, namely $0 \%, 1.5 \%, 5 \%$ and $10 \%$ mass loss. For every corrosion level, three replicate specimens were casted, leading to a total of 24 specimens that were subjected to pull-out tests.

Both rebar types had a nominal diameter of $12 \mathrm{~mm}$. The specifications of the steel were determined on six samples according to EN 10002-1 and are given in table 1. The embedded length was $100 \mathrm{~mm}$ for all specimens. PVC tubes were used to avoid bonding of the remaining rebar sections. Initial experiments have shown that the embedded length for the lowest corrosion levels of the samples with ribbed rebars was too large, and failure of the rebar through rupture was observed at the thread that connected the rebar with the tensile testing machine. Therefore, for these lowest corrosion rates ( $0 \%$ and $1.5 \%$ mass loss), the experiments were repeated with a bond length of $60 \mathrm{~mm}$ (5 times the diameter of the rebar as discussed in [23]). Table 2 gives an overview of the specifications of the different tested specimens.

Table 1: Mechanical properties of reinforcement $[\mathrm{MPa}]$.

\begin{tabular}{ccccccc}
\hline \multirow{2}{*}{ Bar type } & \multirow{2}{*}{$\begin{array}{c}\text { Amount } \\
\text { of tests }\end{array}$} & \multicolumn{2}{c}{ Yield stress } & & \multicolumn{2}{c}{ Tensile strength } \\
\cline { 3 - 4 } & Mean & Std.Dev. & & Mean & Std.Dev. \\
\hline Smooth & 6 & 362.59 & 14.19 & & 498.98 & 45.85 \\
Ribbed & 6 & 489.46 & 37.60 & & 585.04 & 71.92 \\
\hline
\end{tabular}

The rebar was placed horizontally in the center of the wooden mould $\left(150 \times 150 \times 250 \mathrm{~mm}^{3}\right)$ and was protruding from both sides in order to connect the power supply for the accelerated corrosion process afterwards. This geometry was chosen in order to create a symmetric sample during the tests, to avoid crevice corrosion at the entrance point of the rebar in the concrete block, and to represent part of a rebar that is embedded in an actual structure. The concrete composition is shown in table 3. A composition that is representative for existing $\mathrm{RC}$ structures was chosen as the assessment of these structures is the target application. For every batch, also six concrete cubes $\left(150 \times 150 \times 150 \mathrm{~mm}^{3}\right)$ were casted to determine the compressive strength at an age of 28 days and at the age of pull-out testing according to EN 12390-3. Three prisms $\left(150 \times 150 \times 600 \mathrm{~mm}^{3}\right)$ were made to determine the flexural strength at an age of 28 days according to EN 12390-5. The average compressive strength at 28 days was $44.93 \mathrm{MPa}$ with a deviation of $3.40 \mathrm{MPa}$ and the average flexural strength was 5.20 MPa with a deviation of $0.67 \mathrm{MPa}$. After curing for 28 days in a curing room $\left( \pm 20^{\circ} \mathrm{C}, \pm 95 \% \mathrm{RH}\right)$, the specimens were fully immersed in a $5 \%$ sodium chloride solution for three days. Afterwards, the specimens were placed in the accelerated corrosion setup (figure 4) in a climatised room $\left( \pm 20^{\circ} \mathrm{C}, \pm 60 \% \mathrm{RH}\right)$. The accelerated corrosion process and $\mathrm{AE}$ monitoring started at an age of 31 days.

\subsection{Accelerated corrosion process}

The corrosion process was accelerated by an imposed direct current. A constant current density of $100 \mu \mathrm{A} / \mathrm{cm}^{2}$ was chosen as this value was reported in the literature to be the maximum current 
Table 2: Sample specifications.

\begin{tabular}{ccccccc}
\hline Sample name & $\begin{array}{c}\text { Target } \\
\text { corrosion level } \\
\text { (\% mass loss) }\end{array}$ & $\begin{array}{c}\text { Rebar } \\
\text { type } \\
\text { (D12) }\end{array}$ & $\begin{array}{c}\text { Bond } \\
\text { length } \\
\text { (mm) }\end{array}$ & $\begin{array}{c}\text { Amount of } \\
\text { samples }\end{array}$ & $\begin{array}{c}\text { Samples monitored } \\
\text { with AE } \\
\text { during corrosion }\end{array}$ & $\begin{array}{c}\text { Samples monitored } \\
\text { with AE } \\
\text { during pull-out }\end{array}$ \\
\hline $\begin{array}{c}\text { CR0-S1, CR0-S2, } \\
\text { CR0-S3 }\end{array}$ & 0 & Smooth & 100 & 3 & 0 & 3 \\
$\begin{array}{c}\text { CR0-R1, CR0-R2, } \\
\text { CR0-R3 }\end{array}$ & 0 & Ribbed & 100 & 3 & 0 & 3 \\
$\begin{array}{c}\text { CR0-R4, CR0-R5, } \\
\text { CR0-R6 }\end{array}$ & 0 & Ribbed & 60 & 3 & 0 & 3 \\
$\begin{array}{c}\text { CR1-S1, CR1-S2, } \\
\text { CR3-S3 }\end{array}$ & 1.5 & Smooth & 100 & 3 & 1 & 3 \\
$\begin{array}{c}\text { CR1-R1, CR1-R2, } \\
\text { CR3-R3 }\end{array}$ & 1.5 & Ribbed & 100 & 3 & 1 & 3 \\
$\begin{array}{c}\text { CR1-R4, CR1-R5, } \\
\text { CR1-R6 }\end{array}$ & 1.5 & Ribbed & 60 & 3 & 1 & 3 \\
$\begin{array}{c}\text { CR2-S1, CR2-S2, } \\
\text { CR2-S3 }\end{array}$ & 5 & Smooth & 100 & 3 & 1 & 3 \\
$\begin{array}{c}\text { CR2-R1, CR2-R2, } \\
\text { CR2-R3 }\end{array}$ & 5 & Ribbed & 100 & 3 & 1 & 3 \\
CR3-S1, CR3-S2, & 10 & Smooth & 100 & 3 & 1 & 3 \\
$\begin{array}{c}\text { CR3-S3 } \\
\text { CR3-R1, CR3-R2, } \\
\text { CR3-R3 }\end{array}$ & 10 & Ribbed & 100 & 3 & 1 & 3 \\
\hline
\end{tabular}

Table 3: Concrete composition $\left[\mathrm{kg} / \mathrm{m}^{3}\right]$.

\begin{tabular}{cccccc}
\hline CEM I 42.5N & Sand (0/5) & Aggregates (4/14) & Water & Chlorides & W/C \\
\hline 350 & 620 & 1270 & 164 & 7 & 0.46 \\
\hline
\end{tabular}

density occurring in natural conditions [24]. The rebar was connected to the positive side of the DC regulator and acts as an anode. A stainless steel plate was connected to the negative side and acts as a cathode. During exposure, the specimen was partially immersed in a $5 \%$ sodium chloride solution to ensure electrical connectivity and chloride ingress. The setup is shown in figure 4. Crack width measurements were performed every week using a crackmeter with an accuracy of $0.02 \mathrm{~mm}$. In addition, every side of the specimen was photographed. The duration of the accelerated corrosion process was estimated with Faraday's law (Eq. 1).

$$
\Delta m=\frac{t \cdot M \cdot I}{Z \cdot F}
$$

where $\Delta m$ is mass loss in $[\mathrm{g}], t$ is time in $[\mathrm{s}], M$ is molar mass of iron, $I$ is current in $[\mathrm{A}], Z$ is valence which is 2 for iron, and $F$ is Faraday's constant which has the value $96487 \mathrm{C} / \mathrm{mol}$.

\subsection{Pull-out tests}

The pull-out tests were carried out on a testing machine with a capacity of $2500 \mathrm{kN}$. A specially designed loading frame was used. The rebar was pulled down while on top of the specimen, a Linear 


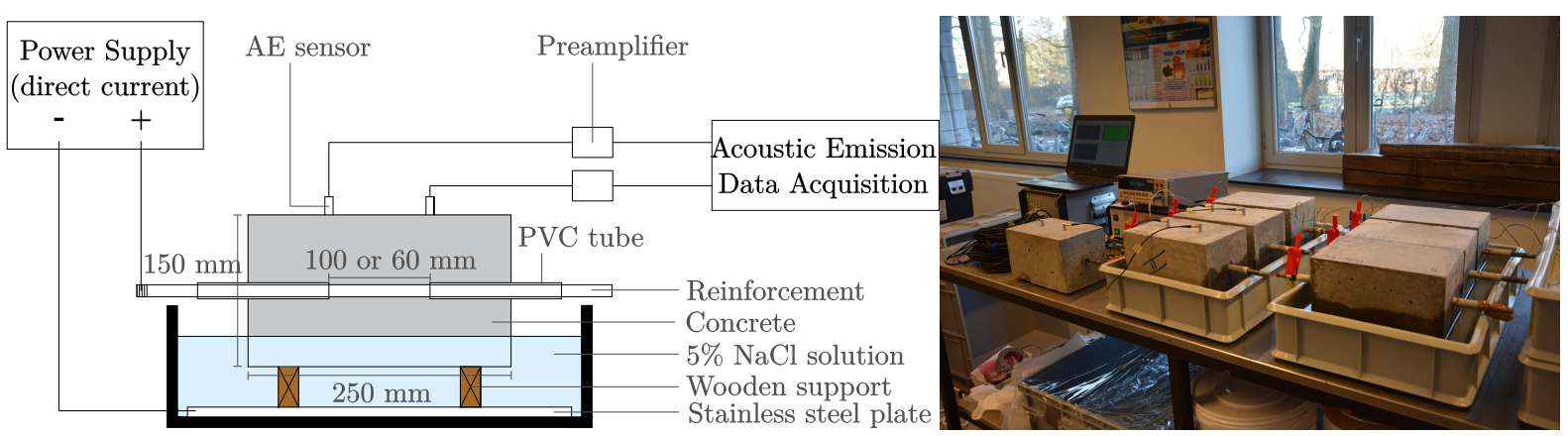

Figure 4: Accelerated corrosion setup.

Variable Differential Transformer (LVDT) was attached to the free rebar end to measure the slip. The specimens were tested in a displacement-controlled regime with a loading speed of $0.3 \mathrm{~mm} / \mathrm{min}$ for the entire test. The bond strength was calculated with equation 2 . The setup for pull-out testing is shown in figure 5.

$$
\tau=\frac{F}{d \cdot \pi \cdot h_{\mathrm{bond}}},
$$

where $\tau$ is the bond strength in [MPa], $F$ is the applied force in $[\mathrm{N}], d$ is the nominal diameter of the rebar in [mm] and $h_{\text {bond }}$ is the bond length in [mm].

\subsection{Acoustic Emission (AE) monitoring}

AE monitoring during the corrosion process and during the pull-out tests was performed with piezoelectric sensors with a flat frequency response between 100-400 kHz (AE104A, Vallen). Sensors were attached on top of the specimen surface with hot melt glue and connected to pre-amplifiers with a fixed gain of $34 \mathrm{~dB}$ (AEP5, Vallen). These pre-amplifiers were connected to a Vallen AMSY-6 acquisition system with six AE channels. AE parameters and waveforms were then stored on a PC and the VallenVisualAE software was used to visualise the data in real time. Matlab was applied for further processing. During the corrosion process, two AE sensors were used, allowing to monitor three samples at the same time with the six channel AE system. The center-to-center distance between the sensors was 60 or $100 \mathrm{~mm}$, equal to the embedded length of the rebar (figure 4 ). During pull-out tests, all six sensors were attached to the specimen tested. The sensor placement is shown in figure 5. The threshold during corrosion and pull-out was set to $40 \mathrm{~dB}$ and $50 \mathrm{~dB}$ respectively, to avoid false detections due to background noise.

\subsection{Determination of corrosion level}

After the pull-out tests, the rebars were taken out of the samples by splitting the concrete in half. The actual mass loss was measured after cleaning the rebar with Clark's solution according to ASTM G1-76. A 3D scan of the rebars of the specimens that were monitored with the AE technique during the corrosion process was made with a Nikon LC60Dx laser scanner. The scanner has a resolution of $60 \mu \mathrm{m}$. The point cloud obtained from the 3D scan was edited into a mesh using GomInspect. From the mesh, a solid was made in AutodeskMeshmixer, and Rhinoceros was used to calculate the volume of the rebar. 


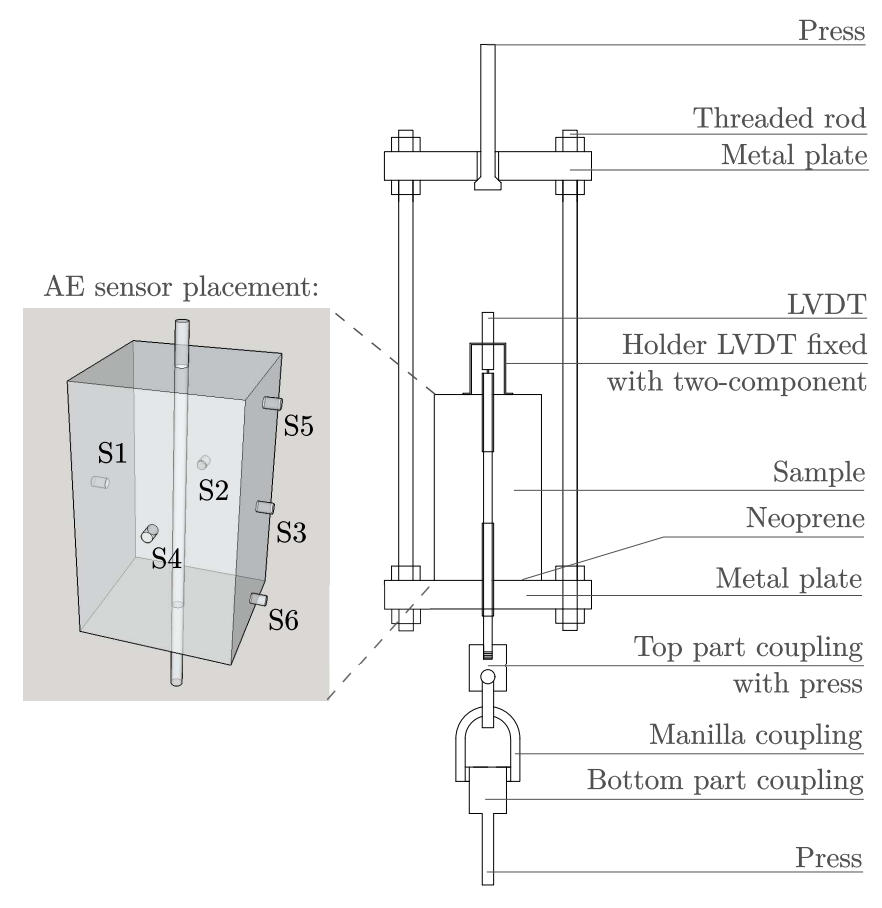

Figure 5: Pull-out test setup and AE sensor configuration.

\section{Results and discussion}

\subsection{Corrosion process}

During the accelerated corrosion process, crack width measurements were performed every week. Samples of the lowest corrosion level (CR1, 1.5\% mass loss) did not crack during the accelerated corrosion test. For the higher corrosion levels (CR2, 5\% mass loss and CR3, 10\% mass loss) specimens showed longitudinal (parallel to the rebar) cracks. For these higher corrosion levels, the average crack widths versus time of corrosion are shown in figure 6. Each crack was measured at nine locations. The average of these nine measurement points was calculated. Most samples showed a longitudinal crack on the surface that was completely immersed in the salt solution (surface A on figure 6). This crack was also noticeable on the sides (surface E and F). One sample was cracked at the side (surface D). The rebar of this sample was not exactly positioned in the middle leading to a slightly smaller concrete cover at the side. It can clearly be observed in figure 6 that the samples with ribbed rebars started to crack earlier than the samples with smooth rebars. The effective steel surface that is bonded with the concrete is larger in the case of a ribbed rebar resulting in larger internal stresses around the ribs.

One sample of each rebar type and each target corrosion level was monitored continuously with the AE technique during the accelerated corrosion process. AE sources were located in real time using a linear localisation algorithm as two sensors were placed on the sample surface. The cumulative localised AE events versus time are presented in figure 7 for all monitored samples. The results are shown against the average crack width. When the sample is not cracked, the amount of events increases almost linearly. AE events are mainly caused by the internal pressure caused by the corrosion products, and micro-cracking. Rust will first fill the small gaps and pores between the steel and concrete and will cause an internal pressure or friction before concrete cracking 


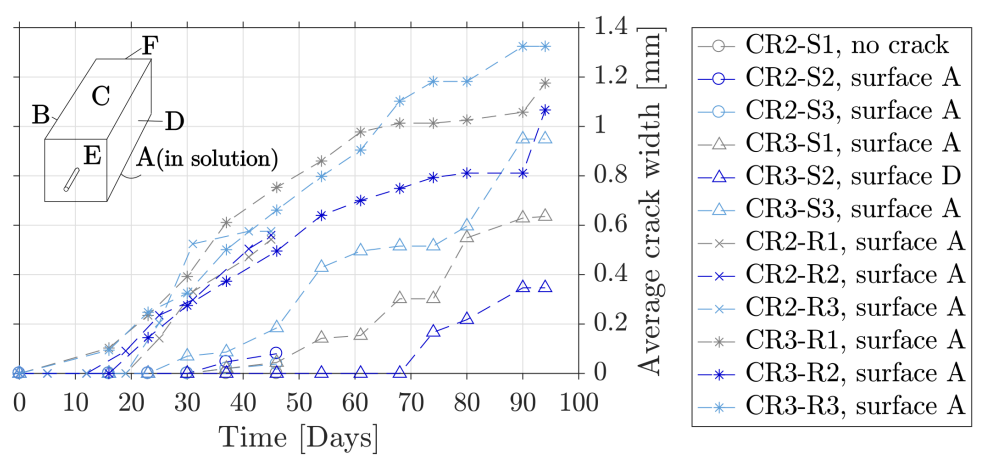

Figure 6: Average crack width versus time with indication of cracked surface.

occurs. The moment of macro-cracking which is indicated by the dark grey area, can clearly be distinguished based on the amount of recorded $\mathrm{AE}$ events as there is a sudden increase. A good agreement between the $\mathrm{AE}$ events and average crack width is also noticeable in terms of slope increase. Similar results were obtained when comparing the cumulative AE energy of the localised events with the average crack width.

A possible relation was searched at between the localised AE events and energy, and mass loss of the rebar which is an innovative approach and has not been performed so far. Figure 8 shows the cumulated localised AE events and cumulated AE energy of these events in comparison with a picture and 3D volume of the rebars of sample CR3-R1 and sample CR2-S1. The AE energy is calculated by squaring and integrating the AE signal. The energy unit (eu) is equal to $10^{-14}$ $\mathrm{V}^{2} \mathrm{~s}$. The corroding part of the rebar was divided in zones of $1 \mathrm{~cm}$. For every centimeter, the amount of located AE events or AE energy of located events was cumulated, and the mass loss was calculated with the $3 \mathrm{D}$ volume obtained from the $3 \mathrm{D}$ scan made after the pull-out test. The mass loss of each zone was determined with a resolution of $0.001 \mathrm{~g}$. For sample CR3-R1 (left), the cumulated AE energy is different from the cumulated AE events. At some points, the cumulated AE energy shows the same trend as the mass loss, but the results are not consistent. Sample CR3$\mathrm{R} 1$ was cracked after the corrosion process. Cracks influence the propagation path of the elastic waves leading to a reduced localisation accuracy. For sample CR2-S1 (right), the cumulated AE events are in good agreement with cumulated AE energy. No surface cracks were detected after the corrosion process on sample CR2-S1. Most damage (mass loss) can be noticed in the middle of the rebar. The same trend can be noticed for the AE events which are located mostly in the middle of the rebar. For both samples, all localised events are shown. These events are originating from different sources, such as the corrosion process itself and concrete cracking. The cracking will therefore strongly influence the results of sample CR3-R1. Similar results were obtained for the other cracked samples CR2-R1 and CR3-S1. In further work, these different AE sources will be distinguished by signal clustering to enable a more accurate damage characterisation.

On figure 9, the correlation between localised AE events and mass loss (left), and AE energy and mass loss (right) was investigated more in detail for sample CR2-S1. The correlation is most clear between the AE energy and mass loss. Except for two points, they show a linear correlation. The trendline shown in figure 9 is determined neglecting the two badly placed points. These two points are located between 70 and $90 \mathrm{~mm}$ (figure 8). The localisation is most accurate in the middle between the two sensors, whereas at the sides the location error can go up to $20 \mathrm{~mm}$. The correlation of sample CR3-R1 are not shown as the results were scattered and therefore no clear 

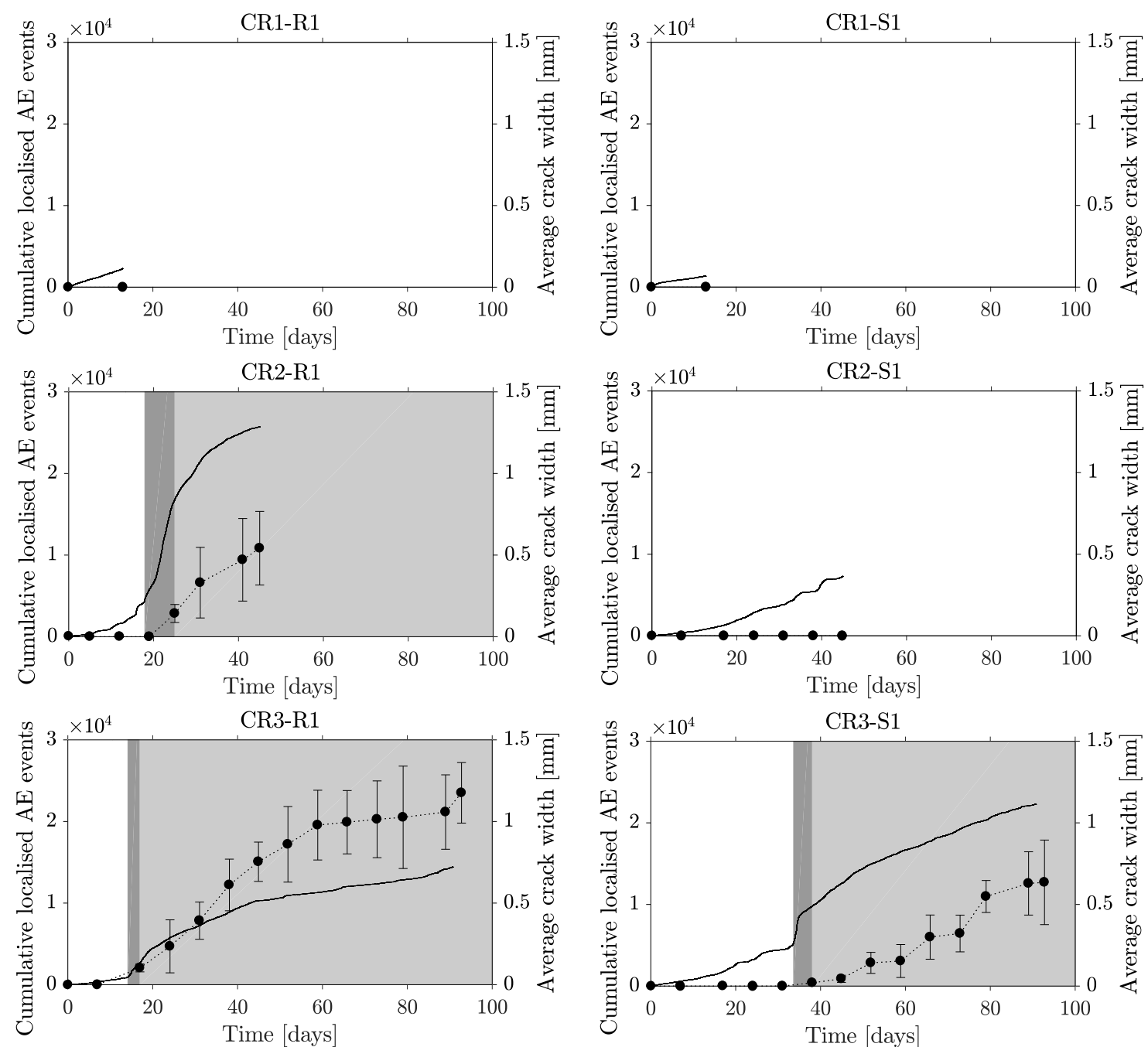

- Cum. loc. AE Event

I Error crack width

Figure 7: Average crack width and cumulative localised AE events versus time for samples CR1-R1 (ribbed rebar, top left), CR1-S1 (smooth rebar, top right), CR2-R2 (ribbed rebar, middle left), CR2-S2 (smooth rebar, middle left), CR3-R1 (ribbed rebar, bottom left), and CR3-S3 (smooth rebar, bottom right). 

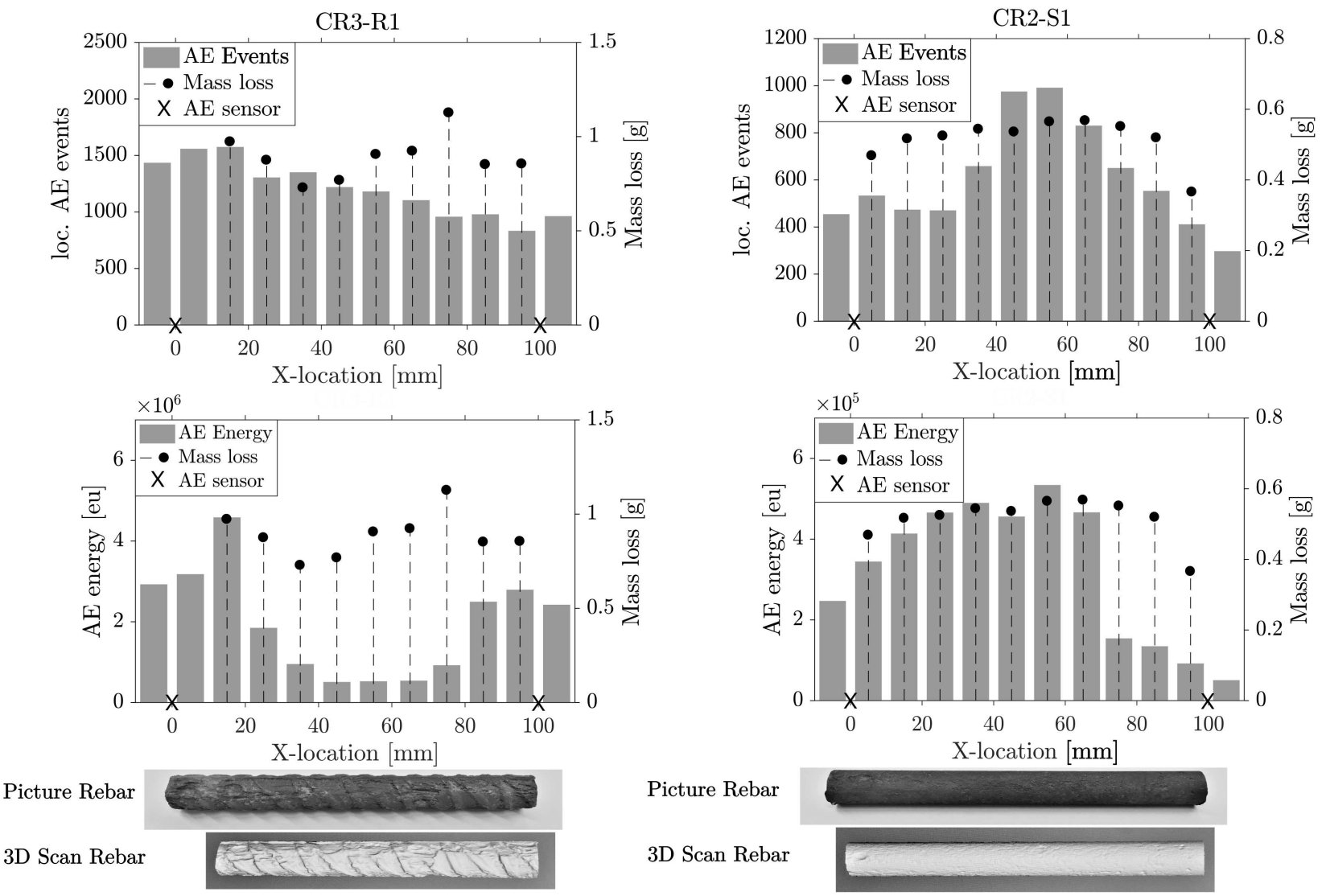

Picture Rebar

3D Scan Rebar

Figure 8: Cumulated amount of AE events (top) and cumulated AE energy (bottom) compared with a picture and 3D volume of the rebars of sample CR3-R1 (ribbed rebar, left) and sample CR2-S1 (smooth rebar, right). 

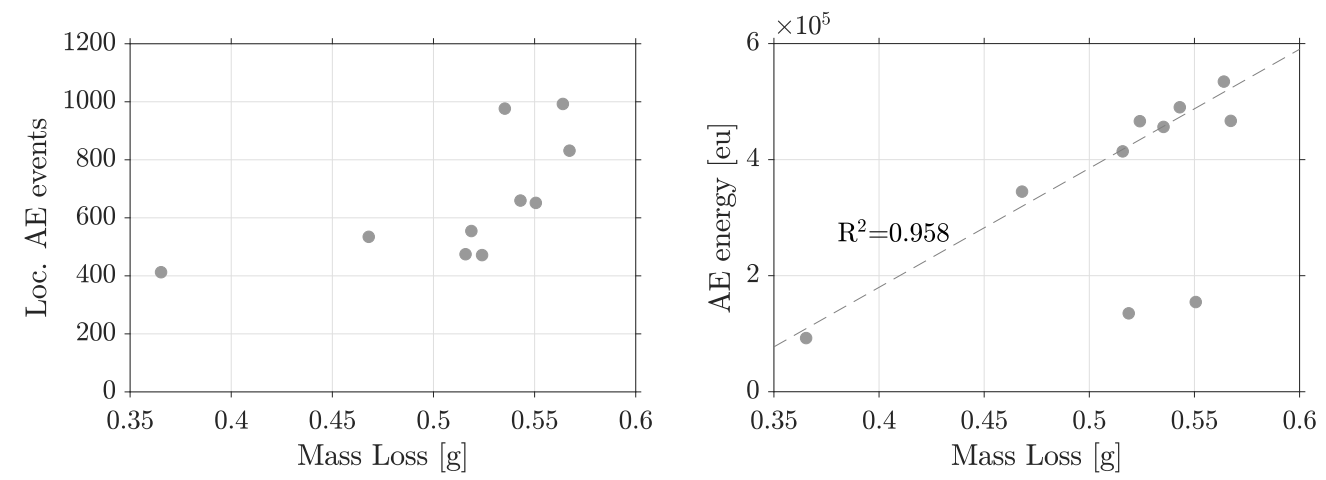

Figure 9: Correlation between localised AE events and mass loss, and AE energy and mass loss for sample CR2-S1.

trend could be noticed. As mentioned before, the crack will clearly influence the results. This way of analysis is very promising, however the current scale might be too small. In further work, the analysis will be repeated on larger specimens.

\subsection{Pull-out tests}

The pull-out tests were executed when the time to reach the target corrosion level according to Faraday's law was exceeded. Table 4 shows a comparison between the designed and reached corrosion level. Also crack widths before and after pull-out testing are given. The measured corrosion level for the lowest target corrosion level exceeded the design value. For higher corrosion levels, the target was mostly not reached. Faraday's law assumes that all current is applied to dissolve iron in the electrochemical reaction, which is not the case. It also does not take into account the concrete permeability and amount of chlorides in the solution.

Figure 10 shows the bond strength versus the slip for the different corrosion levels for samples with ribbed (a) and smooth (b) rebars. The bond strength for the samples with non-corroded ribbed rebars is clearly higher than the bond strength of samples with non-corroded smooth rebars. The ribs of the ribbed rebars provide more resistance against the pull out force. The bond of smooth rebars is only caused by chemical adhesion and friction and thus no mechanical interlocking. For the specimens CR1-R1 and CR1-R3, the bond strength increases with $75 \%$ in comparison with the non-corroded samples. The reinforcement failed due to rupture of the rebar explaining the sudden stop in the graph. Due to the expansive nature of the corrosion products, the rebars are more confined resulting in a higher bond strength and stiffness. The same explanation is valid for the samples with smooth rebars where the increase is even more remarkable, namely an increase by a factor 10. For higher corrosion levels, $5 \%$ and $10 \%$ mass loss, the bond strength decreases for the samples with ribbed rebars as they all showed corrosion-induced cracks before testing. As the cracks are parallel to the rebar and loading direction, the specimens splitted along the already existing corrosion cracks. The bond strength of samples with smooth rebars remains the same for a target corrosion level of $5 \%$ mass loss. Even though fine cracks could be observed before testing, the bond strength is still improved compared with the non-corroded samples. The roughness of the smooth rebar increases as they reach higher corrosion levels resulting in more friction and thus a higher bond strength and decreased slip. When the corrosion level increases, this effect reduces due to larger crack widths. 


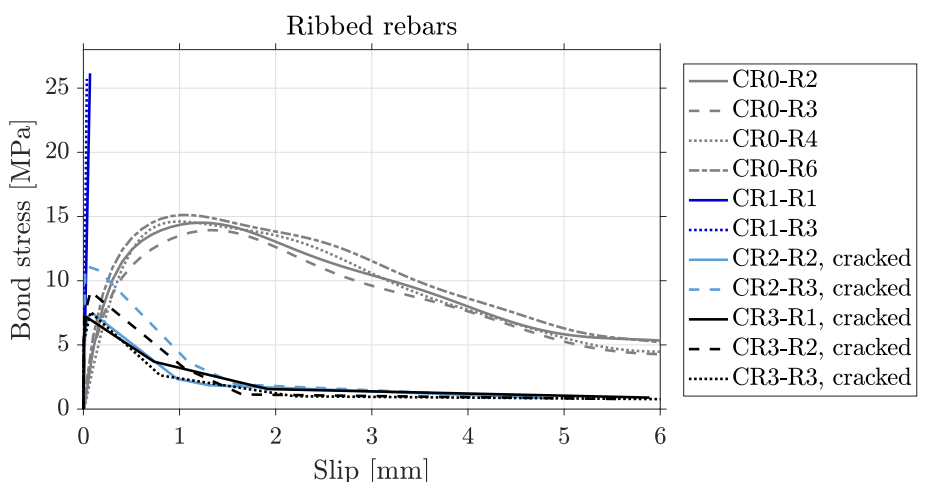

(a)

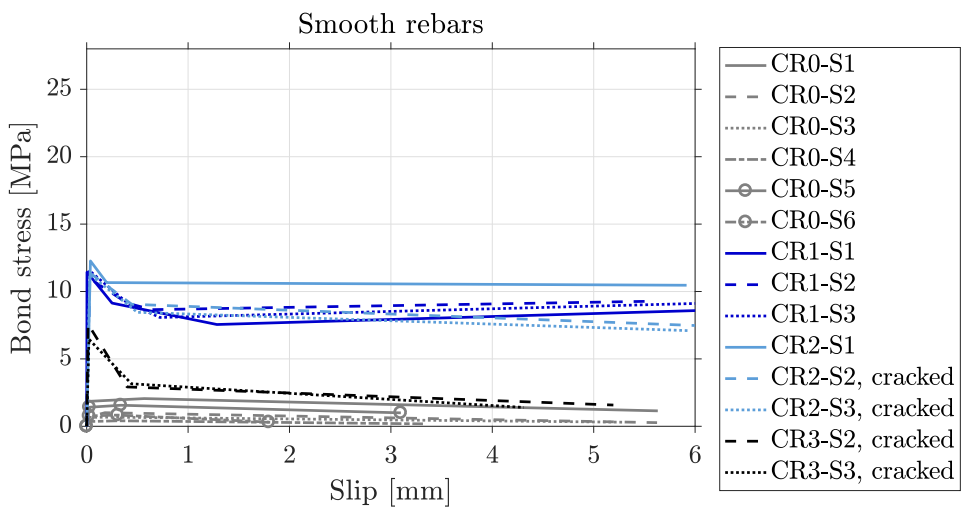

(b)

Figure 10: Relationship between bond stress and slip for samples with (a) ribbed rebars (b) smooth rebars.

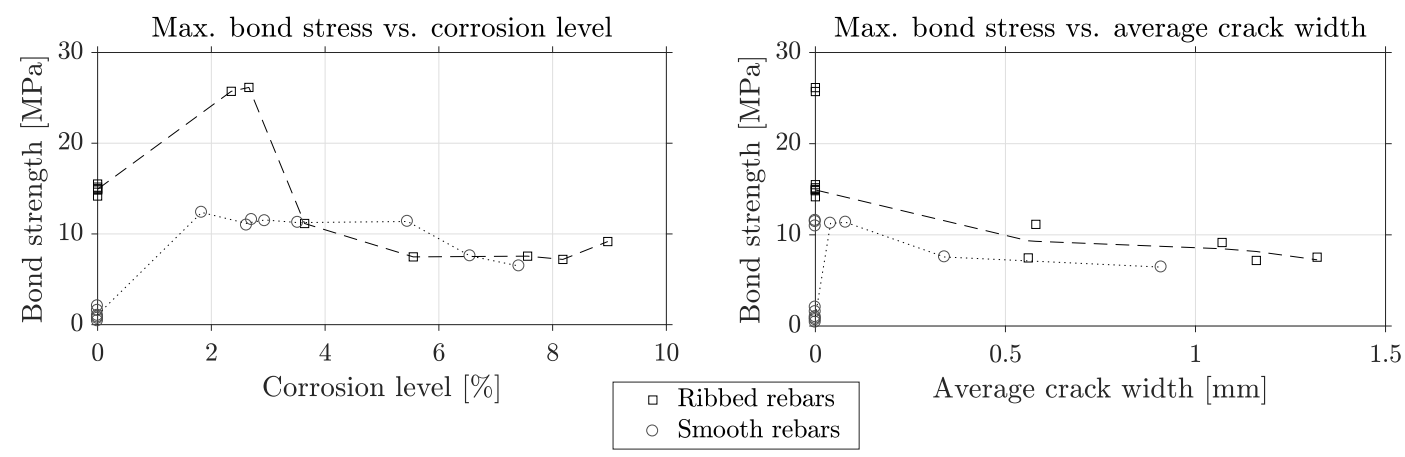

Figure 11: Bond strength versus measured corrosion level (left) and average crack width before testing (right). 
Table 4: Comparison of the designed and measured corrosion level, and crack width before and after pull-out testing; / = value not measured.

\begin{tabular}{cccccc}
\hline Sample name & $\begin{array}{c}\text { Designed } \\
\text { corrosion level } \\
\text { (\% mass loss })\end{array}$ & $\begin{array}{c}\text { Measured } \\
\text { corrosion level } \\
\text { (\% mass loss) }\end{array}$ & $\begin{array}{c}\text { Average crack } \\
\text { width before } \\
\text { testing }(\mathrm{mm})\end{array}$ & $\begin{array}{c}\text { Average crack } \\
\text { width after } \\
\text { testing }(\mathrm{mm})\end{array}$ & $\begin{array}{c}\text { Bond } \\
\text { strength } \\
(\mathrm{MPa})\end{array}$ \\
\hline CR1-R1 & 1.5 & 2.66 & No crack & No crack & 26.15 \\
CR1-R2 & 1.5 & 1.25 & No crack & $/$ & $/$ \\
CR1-R3 & 1.5 & 2.35 & No crack & No crack & 25.72 \\
CR2-R1 & 5 & 3.97 & 0.54 & $/$ & $/$ \\
CR2-R2 & 5 & 5.55 & 0.56 & 2.44 & 7.47 \\
CR2-R3 & 5 & 3.64 & 0.58 & 3.41 & 11.15 \\
CR3-R1 & 10 & 8.18 & 1.16 & 3.21 & 7.19 \\
CR3-R2 & 10 & 8.97 & 1.07 & 4.44 & 9.16 \\
CR3-R3 & 10 & 7.56 & 1.23 & fully split & 7.55 \\
CR1-S1 & 1.5 & 2.94 & No crack & No crack & 11.44 \\
CR1-S2 & 1.5 & 2.62 & No crack & No crack & 10.96 \\
CR1-S3 & 1.5 & 2.71 & No crack & No crack & 11.57 \\
CR2-S1 & 5 & 1.83 & No crack & No crack & 12.37 \\
CR2-S2 & 5 & 5.45 & 0.08 & 0.24 & 11.37 \\
CR2-S3 & 5 & 3.52 & 0.04 & 0.34 & 11.26 \\
CR3-S1 & 10 & 6.07 & 0.64 & $/$ & $/$ \\
CR3-S2 & 10 & 6.55 & 0.34 & 0.84 & 7.57 \\
CR3-S3 & 10 & 7.41 & 0.91 & 2.36 & 6.46 \\
\hline
\end{tabular}

The relation between the bond strength and measured corrosion level, and bond strength versus average crack width is given in figure 11. For samples with ribbed rebars, the bond strength increases for small corrosion levels. As soon as corrosion cracks appear on the concrete surface, the bond strength decreases. On the other hand, for smooth rebars, the performance is better in comparison with the non-corroded samples, even when corrosion cracks are visible on the concrete surface.

Figure 12 shows the correlation between the bond stress $(\tau)$ and slip $(\delta)$ for six representative samples. The samples differ in type of reinforcement and corrosion level. The results are compared with the cumulative AE energy measured during pull-out testing. A planar localisation algorithm was applied to localise the AE sources in 2D using sensors 1, 2, 3 and 4 (see Figure 5 for sensor locations). As many reflections could be noticed, the analysis was only carried out with the localised events lying within $90 \%$ of the sample cross section. A similar approach was applied by Gallego et al. [25].

For the non-corroded sample with a ribbed rebar, CR0-R4 (Figure 12 top left), the $\tau-\delta$ relation can be divided in three stages [26. In stage I, the bond is assured by chemical adhesion formed between the rebar and cement paste during curing. This chemical adhesion is destroyed as soon as the first slip occurs. In stage II, the chemical adhesion breaks down and mechanical interlocking between the ribs and the surrounding concrete will be the major bonding mechanism. The tensile load applied on the rebar will be transferred through the ribs to the surrounding concrete and induces bearing stresses. These bearing stresses cause tensile stresses at the rib tips leading to 

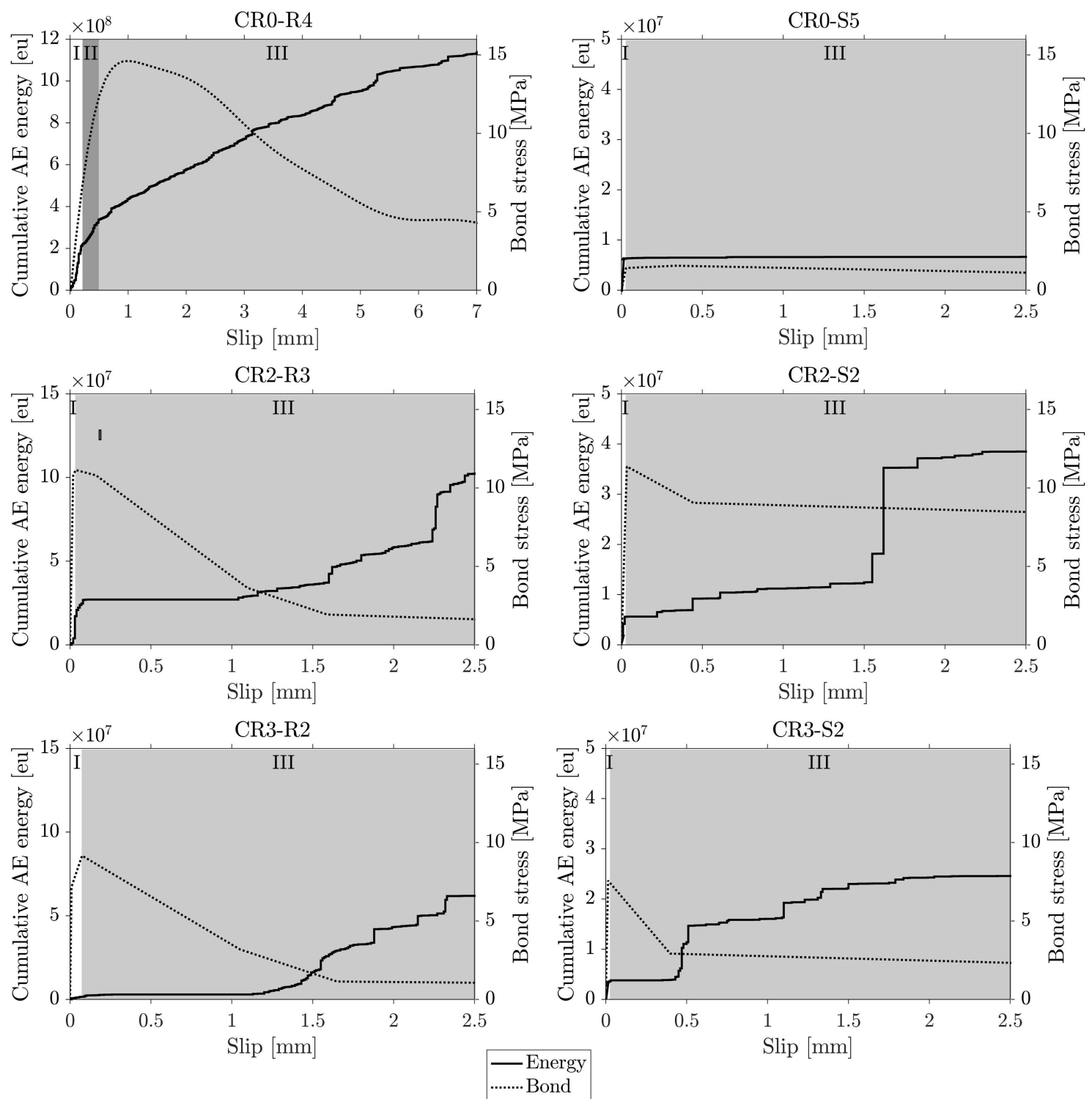

Figure 12: Bond-slip relationships of ribbed and smooth reinforcement compared with AE energy CR0-R4 (top left), CR0-S5 (top right), CR2-R3 (middle left), CR2-S2 (middle right), CR3-R2 (bottom left), and CR3-S2 (bottom right). 


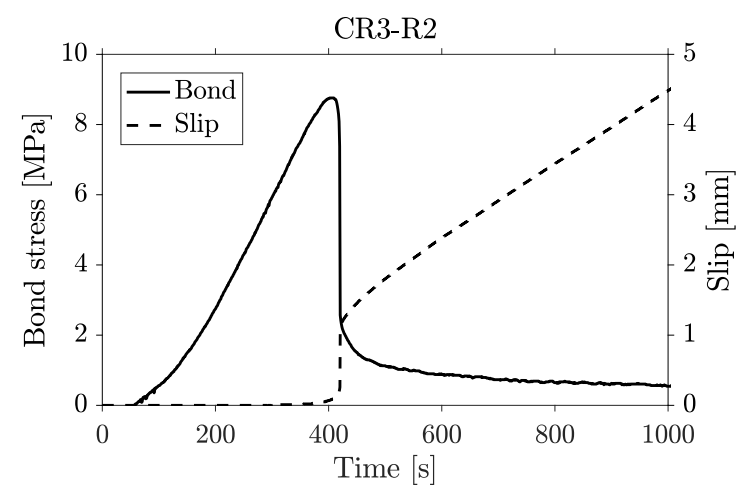

Figure 13: Bond stress and slip versus time for sample CR3-R2.

the formation of transverse micro-cracks in the concrete. This will allow the bar to slip. As the wedging action of the ribs is limited, the concrete will not split. After stage II, the sample can fail due to splitting or pull out. The wedging action will increase by crushing of concrete. This is resisted by hoop stresses in the surrounding concrete. These hoop stresses will induce longitudinal splitting cracks. When the concrete cover is small, these splitting cracks can reach the surface. When there is more confinement, for example a larger concrete cover, splitting will not occur and the bar will be pulled out. The samples fail by sliding of the rebar (stage III). The three stages can be distinguished in the cumulative AE energy pattern. When the chemical adhesion is destroyed, an increase in AE activity can be noticed. In stage II, the AE energy rate reduces. When the bar starts sliding in stage III, the AE energy rate reduces again.

In the case of a non-corroded smooth rebar, CR0-S5 (Figure 12 top right), stage III immediately follows stage I [26]. The bond of smooth rebars is only caused by chemical adhesion and friction. An increase of AE energy can be noticed during stage I. In stage III, friction is the main failure mechanism resulting in a reduction of the detected $\mathrm{AE}$ energy rate.

The corroded samples all showed a longitudinal crack due to the corrosion process causing a reduced confinement. The bond strength suddenly decreases while the slip suddenly increases as can be seen in figure 13 . On the one hand, the sudden displacement is caused by the elastic relaxation of the rebar. The rebar will elongate due to the applied pull-out force (about $0.12 \mathrm{~mm}$ ) but will be prevented from sliding by the embedded length. At a certain force, the bond stress will be too high, the rebar will be released and will return back to its original length. On the other hand, the crack caused by the corrosion process starts to grow. As there is less confinement, the bar starts to slip. For sample CR2-R3 (Figure 12 middle left), an increase in AE energy rate can be noticed in stage I. AE energy increases in stage III due to friction. Sample CR3-R2 (Figure 12 bottom left) shows almost no AE activity during stage I. AE activity starts in stage III due to friction.

In case of corroded smooth reinforcement, the roughness of the rebar increases as they reach higher corrosion levels resulting in more friction and thus a higher bond strength. The same phenomenon can be seen as for the corroded ribbed samples. Also in this case, the most AE energy is released during stage III.

A linear localisation algorithm was applied using sensors 3,5 and 6 (Figure 5) that were placed on one line to investigate the location of debonding. The AE energy of the located AE events as 
a function of time are illustrated in figure 14. The test was divided into four intervals: A-B, B-C, $\mathrm{C}-\mathrm{D}$ and D-E. These intervals are indicated in the bond stress versus time-graph on the top. The intervals are determined as follows:

Interval I (A-B): From the start of the test until 50\% of the maximum bond stress is reached

Interval II (B-C): From 50\% of the maximum bond stress until the maximum bond stress is reached

Interval III (C-D): From the maximum bond stress until the point where the bond stress varies less than $15 \%$ of the final measured bond stress

Interval IV (D-E): From the point where the bond stress varies less than $15 \%$ of the final measured bond stress until the end of the test

For every location zone of $1 \mathrm{~cm}$, the AE energy was cumulated for each time interval and shown perpendicular to the loading direction. The Y-axis indicates the distance between the sensors. Also the bonded length is indicated.

For the uncorroded sample, CR0-R4, the expected upward movement of the debonded area can be distinguished. The AE events located below the bonded length are caused by friction of the PVC tube. In these samples, the PVC tube was pulled out along with the rebar. For the ribbed rebar, more AE energy is released in interval III and IV when the bar is pulled out. The rough surface will result in more friction. For the smooth rebar, sample CR0-S5, most energy is released in the beginning of the test when the chemical adhesion is broken down. In the case of the corroded sample CR2-R3, more AE activity is noticed when the bar is pulled out and is located over the entire embedded length of the concrete. This sample had a longitudinal crack due to corrosion. The crack width increased during pull-out testing leading to emissions along the full height of the sample.

\subsection{Comparison with the literature}

The results obtained in this paper were compared with the literature study that was presented in the introduction. For the samples with ribbed rebars, the results are in good agreement with what was found in the literature for the bond strength versus corrosion level, except for the lowest corrosion level (1.5\% mass loss) (figure 15). This might be due to the relatively large concrete cover thickness in comparison with the diameter of the rebars applied in this study. When looking at the relation between bond strength and crack width (figure 16), the results of the current study follow the same trend as found in the literature. Results of the samples with smooth reinforcement (figure 17) show overall a higher bond strength than the results obtained by Fang et al. 2], again likely due to the relatively large cover thickness. As results can only be compared with one other study, more research on smooth rebars is needed to confirm the results. Many existing structures that are suffering from corrosion are constructed in the sixties and seventies. At that time, many were reinforced with smooth rebars. More research on this rebar type is needed in order to more reliably predict the structural behaviour. Figure 18 shows the relation between bond strength and crack width of smooth rebars, which is not yet available in the literature. This graph can be of interest for inspection-based modelling where the crack width is used as an input. 

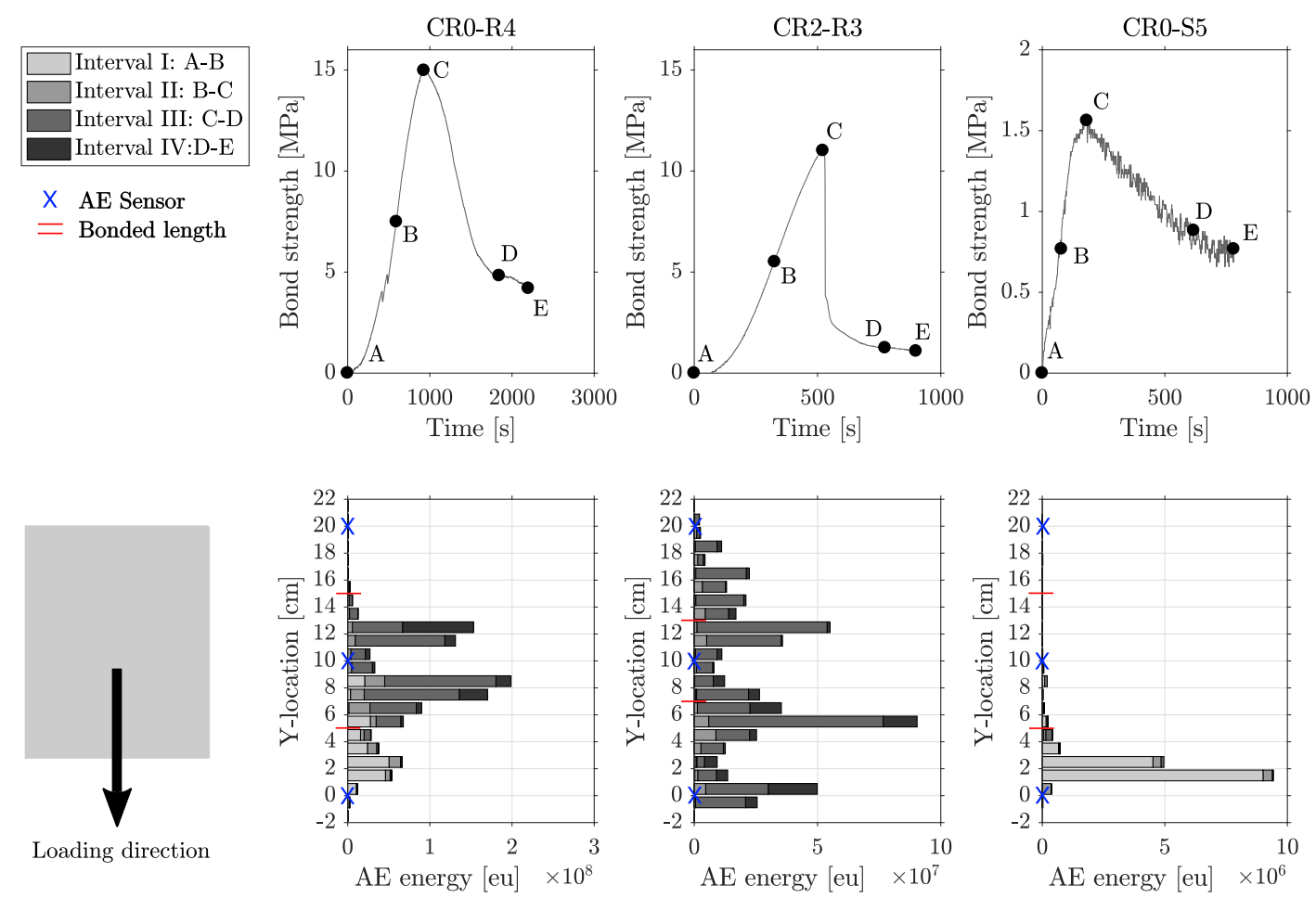

Figure 14: Top: bond stress versus time of representative samples for location analysis of AE events; Bottom: cumulated AE energy of located AE events of sample CR0-R4 (left), CR2-R3 (middle), and CR0-S5 (right).

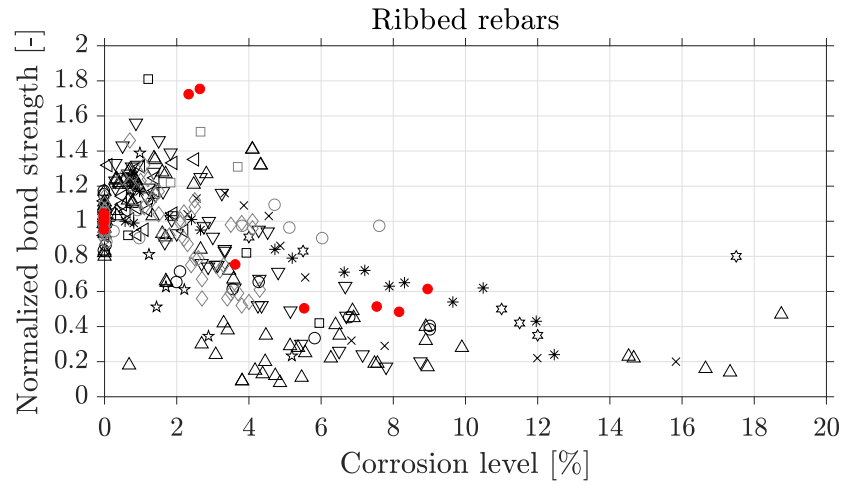

$\triangle$ Yalciner et al. (2012), unconfined

Almusallam et al. (1996), unconfined

- Zhao et al. (2013), unconfined

* Cabrera (1996), unconfined

$\triangleleft$ Chung et al. (2008), unconfined

○ Fang et al. (2004), unconfined

$\nabla$ Al-Sulaimani et al. (1990), unconfined

के Auyeung et al. (2000), unconfined

\& Amleh and Mirza (1999), unconfined

Fang et al. (2004), confined

Zhao et al. (2013), confined

Wu et al. (2016), confined

- Current work

Figure 15: Normalised bond strength versus corrosion level for samples with ribbed rebars including results of the current study. 


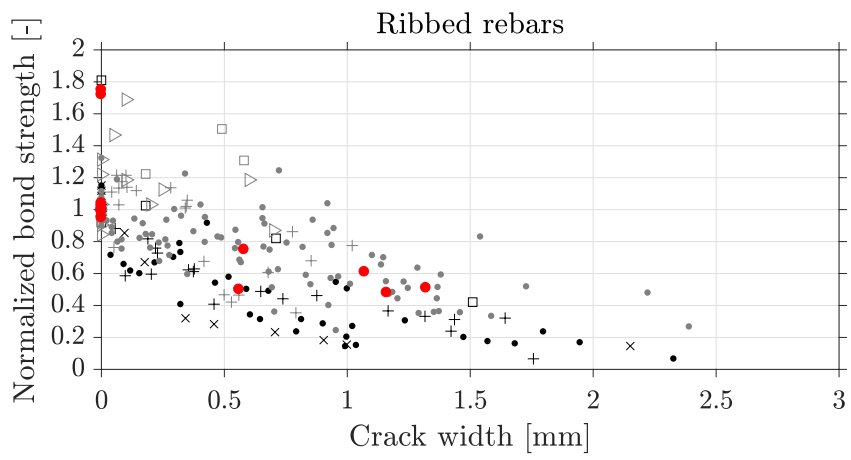

+ Law et al. (2011), unconfined

$\times$ Almusallam et al. (1996), unconfined

- Lin et al. (2017), unconfined

- Zhao et al. (2013), unconfined

+ Law et al. (2011), confined

$\triangleright \mathrm{Li}$ and Yuan (2013), confined

Lin et al. (2017), confined

- Zhao et al. (2013), confined

- Current work

Figure 16: Normalised bond strength versus crack width induced by corrosion for samples with ribbed rebars including results of the current study.

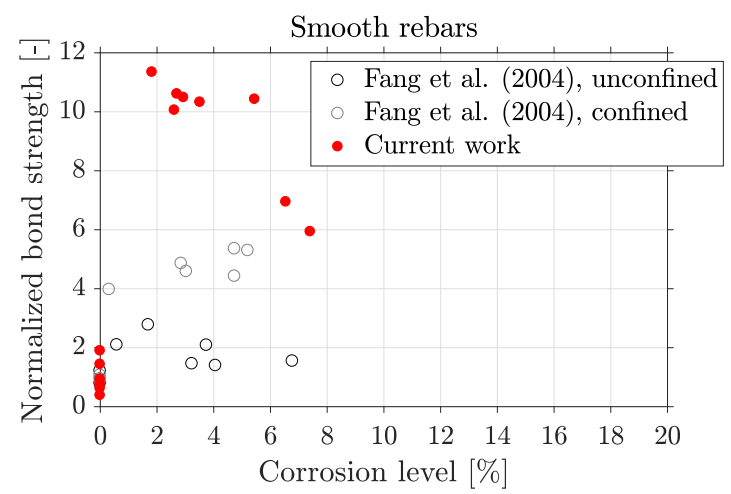

Figure 17: Normalised bond strength versus corrosion level for samples with smooth rebars including results of the current study.

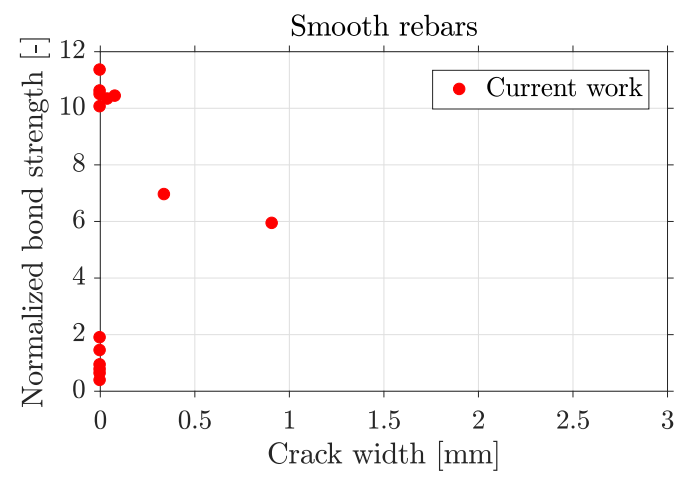

Figure 18: Normalised bond strength versus crack width induced by corrosion for samples with smooth rebars. 


\section{Conclusions}

This paper presented results obtained during the accelerated corrosion process and pull-out testing of reinforced concrete prisms. The specimens had different rebar types (smooth or ribbed) and were corroded up to different target corrosion levels $(0 \%, 1.5 \%, 5 \%$ and $10 \%$ mass loss). The $\mathrm{AE}$ technique was used to monitor the samples. Results show that AE is able to detect damage due to corrosion and that the moment of concrete cracking can be determined from cumulative $\mathrm{AE}$ event curves. AE results need further analysis to distinguish emission from different AE sources such as the corrosion process itself and concrete cracking. Pull-out tests were performed at target corrosion levels. The difference between the type of rebar (ribbed or smooth) and corrosion level could be distinguished from AE curves. Debonding damage was successfully detected, characterised and located from AE results. Results from the discussed experimental program were compared with the literature. Overall, the results are in good agreement except for low corrosion levels, probably due to the larger concrete cover used in this paper.

\section{Acknowledgments}

This research was performed within the framework of project C24/17/042 "Multi-scale assessment of residual structural capacity of deteriorating reinforced concrete structures", supported by Internal Funds KU Leuven.

\section{References}

[1] Y. Auyeung, Bond behaviour of corroded reinforcement bars., ACI Materials Journal 97(2) (2000) $214-221$.

[2] C. Fang, K. Lundgren, L. Chen, C. Zhu, Corrosion influence on bond in reinforced concrete., Cement and Concrete Research 34 (2004) 2159-2167.

[3] K. Lundgren, Effect of corrosion on the bond between steel and concrete: an overview., Magazine of Concrete Research 59(6) (2007) 447-461.

[4] C. Fang, K. Lundgren, M. Plos, K. Gylltoft, Bond behaviour of corroded reinforcing steel bars in concrete., Cement and Concrete Research 36(10) (2006) 1931-1938.

[5] J. G. Cabrera, Deterioration of concrete due to reinforcement steel corrosion., Cement and Concrete Composites 18 (1996) 47-59.

[6] G. J. Al-Sulaimani, M. Kaleemullah, I. A. Basunbul, Rasheeduzzafart, Influence of corrosion an cracking on bond behavior and strength of reinforced concrete members., ACI Structural Journal 87(2) (1990) 220-231.

[7] Y.-Z. Wu, H.-L. Lv, S.-H. Zhou, Z.-N. Fang, Degradation model of bond performance between deteriorated concrete and corroded deformed steel bars., Construction and Building Materials 119 (2016) 89-96.

[8] H. Yalciner, S. Sensoy, An experimental study on the bond strength between reinforcement bars and concrete as a function of concrete cover, strength and corrosion level., Cement and Concrete Research 42 (2012) 643-655.

[9] H.-S. Lee, T. Noguchi, F. Tomosawa, Evaluation of the bond properties between concrete and reinforcement as a function of the degree of reinforcement corrosion., Cement and Concrete Research 32 (2002) 1313-1318.

[10] Y. Zhao, H. Lin, K. Wu, W. Jin, Bond behaviour of normal/recycled concrete and corroded steel bars., Construction and Building Materials 48 (2013) 348-359.

[11] A. A. Almusallam, A. S. Al-Gahtani, A. R. Aziz, Rasheeduzzafart, Effect of reinforcement corrosion on bond strength., Construction and Building Materials 10(2) (1996) 123-129.

[12] L. Amleh, S. Mirza, Corrosion influence on bond between steel and concrete., ACI Structural Journal 96 (1999) $415-423$

[13] L. Chung, J.-H. Jay Kim, S.-T. Yi, Bond strength prediction for reinforced concrete members with highly corroded reinforcing bars., Cement and Concrete Composites 30 (2008) 603-611.

[14] D. W. Law, D. Tang, T. K. C. Molyneaux, R. Gravina, Impact of crack width on bond: confined and unconfined rebar., Materials and Structures 44 (2011) 1287-1296.

[15] F. Li, Y. Yuan, Effects of corrosion on bond behavior between steel strand and concrete., Construction and Building Materials 38 (2013) 413-422. 
[16] H. Lin, Y. Zhao, J. Ozbolt, H. W. Reinhardt, Bond strength evaluation of corroded steel bars via the surface crack width induced by reinforcement corrosion., Engineering Structures 152 (2017) 506-522.

[17] M. Wevers, Listening to the sound of materials: Acoustic emission for the analysis of material behaviour., NDT and E International 30(2) (1997) 99-106.

[18] C. Jirarungsatian, A. Prateepasen, Pitting and uniform corrosion source recognition using acoustic emission parameters., Corrosion Science 52 (2010) 187-197.

[19] M. Fregonese, H. Idrissi, H. Mazille, L. Renaud, Y. Cetre, Initiation and propagation steps in pitting corrosion of austenetic stainless steels: monitoring by acoustic emission., Corrosion Science 43 (2001) 624-641.

[20] D. J. Yoon, W. J. Weiss, S. P. Shah, Assessing damage in corroded reinforced concrete using acoustic emission., ASCE Journal of Engineering Mechanics 126(3) (2000) 273-283.

[21] M. Ohtsu, Y. Tomoda, Phenomenological model of corrosion process in reinforced concrete identified by acoustic emission., ACI Materials Journal 105(2) (2007) 194-199.

[22] C. Van Steen, L. Pahlavan, M. Wevers, E. Verstrynge, Localisation and characterisation of corrosion damage in reinforced concrete by means of acoustic emission and x-ray computed tomography., Construction and Building Materials 197 (2019) 21-29.

[23] RILEM CEB FIP, Bond test for reinforcing steel: Pull-out test., Materials and Structures 3(15) (1970) $175-178$.

[24] C. Andrade, C. Alonso, Corrosion rate monitoring in the laboratory and on-site., Construction and Building Materials 10(5) (1996) 315-328.

[25] A. Gallego, A. Benavent-Climent, E. Suarez, Concrete-galvanized steel pull-out bond assessed by acoustic emission., Journal of Materials in Civil Engineering 28(2) (2016) 1-8.

[26] Fédération international du béton (fib), Bond of reinforcement in concrete, fib bulletin 10 . 